\title{
Lejos de la guerra. Relatos de Malvinas en los primeros años de la democracia
}

\author{
Lara Segade* \\ UBA - CONICET
}

\begin{abstract}
Resumen
A partir de la constatación de que en los relatos de la guerra de Malvinas lo bélico es o bien débil o bien un juego y que sus protagonistas son ante todo víctimas o desertores, en este trabajo se busca reflexionar acerca de los diversos factores que, de 1982 hasta hoy, contribuyeron a obturar la narración de la guerra (esto es, los combates, los armamentos, las conductas heroicas, las estrategias, la posibilidad de morir pero también de matar), priorizando en cambio otras zonas del acontecimiento. Puntualmente, se hace hincapié en el modo en que se articula esta obturación en dos textos fundamentales escritos y publicados muy tempranamente, uno de corte testimonial -Los chicos de la guerra, de Daniel Kon-y otro literario -Los pichiciegos, de Rodolfo Fogwill-.
\end{abstract}

\section{Palabras claves}

Guerra de Malvinas, relato, épica, ficción, testimonio

\begin{abstract}
Stories about the Falklands War display either a weak representation of the war or portray it as a game; their main characters are either victims or deserters. This work reflects on the different reasons that contributed, from 1982 till this day, to obtrude the chronicle of the war (i.e., the combats, the weaponry, the heroic behaviors, the strategies, the possibility of dying but also of killing) by focusing, in contrast, on other aspects of the event.

In particular, this paper delves into the ways in which this obtrusion is articulated in two central texts, both written and published very early: a testimonial story, Los chicos de la Guerra by Daniel Kon, and a literary novel, Los pichiciegos by Rodolfo Fogwill.
\end{abstract}

\section{Keywords}

Falklands' war, stories, epic, fiction, testimony

\footnotetext{
* Investigadora del Instituto de Literatura Hispanoamericana de la Facultad de Filosofía y Letras de la Universidad de Buenos Aires

Esta obra está sujeta a la Licencia Reconocimiento-NoComercial-Compartirlgual 4.0 Internacional de Creative Commons. http://creativecommons.org/licenses/by-nc-sa/4.0/ 


\section{Lejos de la guerra}

I.

De todos los textos de diversa índole que se publican o circulan durante la guerra de Malvinas y en los años siguientes y que dan cuenta del acontecimiento, se destacan fundamentalmente dos: por un lado, Los pichiciegos, novela de Rodolfo Fogwill y, por el otro, Los chicos de la guerra, recopilación de testimonios realizada por el periodista Daniel Kon. ${ }^{1}$ Se destacan, por un lado, porque inauguran los dos modos principales en que Malvinas será contada: la ficción y el testimonio. Por otro lado, por la enorme difusión que han tenido. Después de su primera circulación en fotocopias, Los pichiciegos fue editada sucesivamente en 1983, 1994, 2006 y 2010 y en los últimos años se convirtió en lectura frecuente en el ámbito educativo secundario. El libro Los chicos de la guerra, entretanto, contó con trece reediciones entre 1982 y 1984, además de una versión fílmica que fue vista en cine por casi 700.000 espectadores. $^{2}$

Pero sobre todo Los pichiciegos y las dos versiones de Los chicos de la guerra -el libro y el film- se destacan porque imprimen al relato de Malvinas el que será su sello distintivo: el de que sea justamente la guerra, con sus combates, sus tácticas, sus héroes, lo que menos aparece explicitado en el relato. Los pichiciegos transcurre en una cueva donde se esconde un grupo de soldados, que por medio de intercambios comerciales se procura de lo necesario para sobrevivir hasta que termine la guerra. Así, la novela inaugura una literatura de Malvinas cuyo centro no está en el campo de batalla sino en los márgenes, y cuya figura principal no es el héroe sino el desertor. Pero la guerra parece volverse irrepresentable también para aquellos que la vivieron, para quienes el trauma permanece entonces como tal, esto es, sin elaborar. En Los chicos de la guerra -aunque, como veremos, más en la película que en el libro- las historias personales que fueron interrumpidas por la guerra, la presentación de los soldados como víctimas, en especial de sus superiores, y la interpretación histórica y política de los hechos priman sobre las escenas de combates, la descripción de armamentos o la presentación de conductas heroicas.

\footnotetext{
1 Otro texto relevante es la respuesta de León Rozitchner a la declaración de apoyo a la guerra firmada por un grupo de intelectuales argentinos exiliados en México, más tarde editada en un libro con el título Malvinas: de la guerra sucia a la guerra limpia. A su vez, Néstor Perlongher publicó una serie de artículos relativos a Malvinas durante su exilio en San Pablo, dirigidos también contra quienes apoyaban la guerra: "Todo el poder a Lady Di", en la revista Persona en 1982; "La ilusión de unas islas", en la revista Sitio en 1983 y "El deseo de unas islas", en la revista Utopía en 1985, todos recopilados en Prosa plebeya. Por otro lado, en el ámbito literario, cabe mencionar el cuento de Carlos Gardini, "Primera línea", que obtuvo el premio "Círculo de lectores" en 1982, otorgado por un jurado compuesto, entre otros, por Jorge Luis Borges y José Donoso; la nouvelle "La causa justa" de Osvaldo Lamborghini (1983) y las novelas A sus plantas rendido un león (1986) y Arde aún sobre los años, de Fernando López. En cuanto al relato testimonial, también en 1982 aparece Así lucharon, una recopilación de relatos de militares realizada por Carlos Túrolo que, en los años siguientes contará casi con tantas reediciones como Los chicos de la guerra. Entretanto, en 1985 el ex combatiente Daniel Terzano publica el único testimonio novelado de la guerra de Malvinas: 5000 adioses a Puerto Argentino.

${ }^{2}$ La película fue la segunda en cantidad de espectadores, después de Camila, estrenada el mismo año, que fue uno de los mayores éxitos de taquilla de la historia del cine argentino.
} 


\section{Lara Segade}

A partir entonces de la constatación de que, aunque con matices, el referente bélico es débil tanto en las ficciones como en los testimonios -tendencia que por otra parte se irá profundizando durante las décadas del ochenta, noventa, y todavía en los dos mil, aunque entonces comenzará a ser, también, parcialmente modificada-, es posible revisar las lecturas prevalecientes, que han tendido a la separación genérica de los relatos de Malvinas.

En los años noventa, Martín Kohan fue el primero en considerar a los relatos de Malvinas como un corpus, para señalar que Los pichiciegos y Los chicos de la guerra fundan los dos órdenes narrativos de Malvinas como un contraste, en el que la literatura farsesca se contrapone, punto por punto, al drama testimonial:

Por un lado, la literatura representa una farsa, una farsa de la guerra y de la identidad nacional, donde lo más farsesco, por lo pronto, son las propias identidades [...] Hay en la literatura toda la risa que en los relatos testimoniales resulta tan inverosímil como imposible, inadecuada, intolerable. Los quiebres de la derrota, expresados como lamento en los testimonios, se recuperan, realimentan el credo nacional, y eliminan esa distancia descreída e irónica que está en la base de las narraciones literarias. ${ }^{3}$

En Los pichiciegos, según Kohan, la lógica bélica, basada en el enfrentamiento de dos naciones cuyos valores son exaltados por quienes pertenecen a cada una de ellas, es relegada por la lógica de la supervivencia subterránea. Narrativamente, ello supone un reemplazo de la épica por la farsa. ${ }^{4}$ Como contrapartida, a partir de la modalidad que inaugura Los chicos de la guerra, los relatos testimoniales serán definidos por Kohan como "versiones del lamento por la derrota", que solo pueden contar la guerra como drama y dejan en pie "los fundamentos de la fe nacionalista". En ese sentido, los testimonios se aproximan a las versiones triunfalistas que circularon durante la guerra en los comunicados oficiales y la prensa: "aunque opuestas, al parecer, ambas inflexiones integran una misma concepción de la fábula nacional: la que erige héroes, gloriosos si ganan, inmolados si pierden, pero héroes al fin". ${ }^{5}$

Sin embargo, la propia idea de un reparto genérico resulta confusa, puesto que ya los textos fundantes del relato de Malvinas proponen una serie de

\footnotetext{
${ }^{3}$ Martín Kohan. "El fin de una épica". Punto de vista; №64. Buenos Aires, agosto de 1999; pág. 6. Algunas de las conclusiones de este artículo ya habían sido adelantadas por Kohan en "Transhumantes de neblina", escrito en colaboración con Adriana Imperatore y Oscar Blanco en 1993.

4 Gran parte de la crítica literaria posterior ha retomado estos postulados de Kohan. Julio Schvartzman ve a los pichiciegos como pícaros: "Los pichiciegos elige la perspectiva y la lengua de una picaresca de guerra, de la corrosión de los límites entre los bandos, de la negativa cínica a hablar en serio de los valores involucrados" (pág. 139). Más recientemente, Elsa Drucaroff extremó la posición al afirmar que, en la novela "la entonación cínica y juguetona de la escritura" no permite que nada "alcance dimensión dramática" (pág. 299). Asimismo, en Islas imaginadas, primer abordaje sistemático y de largo aliento de las ficciones de Malvinas consideradas como un todo, la noción de farsa constituye uno de los ejes centrales del análisis, de manera que se retoma y refuerza, allí, la asociación entre ficción y farsa postulada por Kohan para el caso de Malvinas.

${ }^{5}$ Martín Kohan. "El fin de una épica”. Punto de vista; №64. Buenos Aires, agosto de 1999; pág. 6.
} 


\section{Lejos de la guerra}

entrecruzamientos entre lo ficcional y lo testimonial. Por un lado, la novela de Fogwill está construida como una desgrabación de una serie de entrevistas al único pichiciego sobreviviente, es decir, la ficción es una puesta en escena de lo testimonial. Por otro lado, el libro de Kon sirvió de base para la película Los chicos de la guerra, que es una ficcionalización de los testimonios. En la trasposición, además, se realzan los aspectos dramáticos, asociados a una mirada de la guerra como interrupción de la vida y de los soldados como víctimas, y en cambio, se relegan las escenas bélicas que, aunque débilmente, sí aparecían en los testimonios del libro, lo que permitía que sus enunciadores asumieran un posicionamiento menos pasivo. En ese sentido, el film Los chicos de la guerra opera retrospectivamente sobre el libro, subsumiéndolo e invisibilizando sus rasgos distintivos, el principal de los cuales es precisamente ese: la encarnación por parte de los soldados de una agencia en el relato de su experiencia, lo cual redunda en una presencia más fuerte del referente bélico en el libro.

Es por eso que el rasgo que postulamos como central en los relatos de Malvinas, la debilidad del referente bélico, en primer lugar debe ser pensado en la tensión entre lo ficcional y lo testimonial y no en su separación y, luego, en relación con una serie de factores tanto históricos como literarios. Entre los históricos, por un lado, figuran las características peculiares de esta guerra, sobre todo, que la mayor parte del tiempo que los soldados pasaron en las islas haya sido de espera y no de combate; por otro lado, las características de la posguerra, fundamentalmente las dificultades para circular que encontraron los relatos de un hecho de guerra en el marco de la naciente democracia, que buscaba asentar sus bases sobre un relato pacificador y marcar un corte tajante con la violencia del período precedente. Pero, también, la debilidad del referente bélico en los relatos de Malvinas puede pensarse en relación con una dimensión literaria: el decaimiento general de la épica como forma narrativa que parece haber sido todavía más profundo en el caso de Malvinas, conflicto en cuya representación, mayoritariamente, no han intervenido siquiera elementos épicos aislados, como la construcción de figuras heroicas o la focalización del relato en combates en los que o se mata o se muere. ${ }^{6}$

\section{II.}

El proceso de refundación institucional que tiene lugar en Argentina a partir de 1983 hasta cierto punto puede ser pensado a partir de algunos de los desarrollos que Michel Foucault desarrolló en relación con el nacimiento de los estados modernos. En especial, las conferencias, dictadas en el Collège de France, que integran Defender la sociedad, donde Foucault propone un relato histórico en

\footnotetext{
${ }^{6}$ La caída de la épica en el mundo moderno ha sido trabajada por Mijail Bajtín en "Épica y novela". Recientemente, Fredric Jameson ha retomado la cuestión de la épica en el marco de una reflexión sobre el realismo.
} 


\section{Lara Segade}

el que el conflicto, la guerra o la amenaza de guerra ocupan un lugar central. Lejos de constituir una excepción como sostiene la hegemónica historia republicana, la guerra está entramada con la paz. Esto quiere decir que los estados modernos, al consolidarse, no dejan atrás la guerra de la que nacieron sino que la incorporan. De ese modo, Foucault propone, como clave de lectura histórica, una inversión de la conocida fórmula de Karl von Clausewitz -la guerra como continuación de la política por otros medios-: la política como continuación de la guerra por otros medios. En esta clave,

el papel del poder político sería reinscribir perpetuamente esa relación de fuerza, por medio de una especie de guerra silenciosa, y reinscribirla en las instituciones, en las desigualdades económicas, en el lenguaje, hasta en los cuerpos de unos y otros" y, por lo tanto, nunca se escribirá "otra cosa que la historia de esta misma guerra, aunque se escribiera la historia de la paz y sus instituciones. ${ }^{7}$

En el caso argentino, se tratará ante todo, de silenciar la guerra en dos sentidos: en primer lugar, de dejar atrás la violencia del período precedente; en segundo lugar, de tomar distancia de la verdadera guerra que tuvo lugar en 1982 y de la cual, en gran medida, nace la democracia. Como señala Graciela Speranza, la guerra de Malvinas es vista como "la evidencia incómoda de una paradoja histórica: el último capítulo vergonzante de la dictadura militar y, al mismo tiempo, el prólogo de la esperada vuelta a la democracia". 8 En palabras de Federico Lorenz, la incomodidad provenía de la contradicción que se producía "entre los intentos por construir una cultura 'pacifista' basada en los valores democráticos y de los derechos humanos, y la demanda de conmemoración de un hecho 'guerrero' en un país cuya identidad cultural estaba fuertemente marcada por la presencia militar en el panteón nacional". ${ }^{9}$ El resultado fue un conjunto de políticas con las que, durante el gobierno de Raúl Alfonsín, se quiso desmilitarizar a la sociedad pero que redundaron en lo que se conoció como "desmalvinización". ${ }^{10}$

\footnotetext{
${ }^{7}$ Michel Foucault. Defender la sociedad. Buenos Aires, Fondo de Cultura Económica, 2010; pág. 29.

${ }^{8}$ Graciela Speranza. "Cómo se cuenta una guerra". Clarín. Buenos Aires, 26 de marzo de 2000. Disponible en http://edant.clarin.com/suplementos/cultura/2000/03/26/e-00601d.htmp

${ }^{9}$ Federico Lorenz. Las guerras por Malvinas. Buenos Aires, Edhasa, 2006; pág. 188.

10 El concepto de "desmalvinización" lo acuñó el sociólogo francés Alain Rouquié en una entrevista que le hiciera Osvaldo Soriano para la revista Humor en marzo de 1983. Allí, Rouquié sostuvo: "Eso es muy importante: desmalvinizar. Porque para los militares las Malvinas serán siempre la oportunidad de recordar su existencia, su función y, un día, de rehabilitarse. Intentarán hacer olvidar la 'guerra sucia' contra la subversión y harán saber que ellos tuvieron una función evidente y manifiesta que es la defensa de la soberanía nacional (...) Malvinizar la política argentina agregará otra bomba de tiempo en la casa Rosada" (cfr. Federico Lorenz, op.cit.; pág. 141). Entre las medidas que formaron parte de la "desmalvinización" figura el decreto del gobierno de Raúl Alfonsín por el cual se trasladaba al 10 de junio el feriado nacional establecido para el 2 de abril por una ley de facto de 1983. El decreto, por medio del cambio de fecha, recuperaba la historia de la instalación de Luis Vernet en las islas en 1829 y de ese modo buscaba separar la guerra de 1982 del reclamo histórico de soberanía; es decir, el ámbito de la ley del de la guerra. En efecto, el 10 de junio no se conmemora la guerra sino el "Día de la afirmación de los derechos argentinos sobre las Malvinas, Islas y Sector Antártico".
} 


\section{Lejos de la guerra}

En ese contexto, era necesario encontrar un relato que permitiera que la guerra fuera asimilada por la democracia, es decir, que operase respecto de Malvinas de un modo similar al Nunca Más respecto de la dictadura. En efecto, como sostuvo Carlos Gamerro, "El Nunca Más fue el texto fundamental del período: un informe, cuyo fin principal era el de establecer la verdad de los hechos, pero también una colección de relatos, que funda un género discursivo: el Decamerón o Las mil y una noches de los años oscuros".11 La estructura narrativa que proponía ese relato es la que se conoció como "teoría de los dos demonios": una explicación colectiva para la violencia política y la represión de los años previos a partir de la imagen de un enfrentamiento entre dos terrorismos, uno de izquierda y otro de derecha. El resultado es la imagen de una sociedad ajena al enfrentamiento y, por tanto, víctima inocente, que, durante los primeros años de la democracia, resulta funcional al impulso de dejar atrás el horror de la dictadura. En relación con esto, Pilar Calveiro destaca la configuración en estos relatos del desaparecido como víctima inocente y señala que durante hasta 1983 esto permitía eludir la acusación de subversivos con la que la dictadura justificaba su exterminio; por otro lado, posibilitaba que los organismos de derechos humanos se constituyeran y actuaran en tanto defensores de la vida inocente. Una vez en democracia, en cambio,

el recurso a la figura de la víctima inocente fue parte del triunfo del proyecto militar, un triunfo armado pero también político e ideológico, que logró no solo la eliminación de una alternativa política específica sino la "desaparición" de la política misma, de su validez y sentido como práctica social colectiva. A su vez, al reivindicar al "inocente" apolítico como verdadera víctima, la sociedad se identificaba con él, como igualmente "inocente" y ajena al enfrentamiento, eludiendo así las diversas responsabilidades que le cabían en relación con la política de desaparición de personas. ${ }^{12}$

Es en ese marco que la guerra de Malvinas despliega toda su potencia de acontecimiento "incómodo", que dramáticamente encarna, como en nadie, en los que estuvieron ahí. En sus primeras apariciones públicas y en sus primeros testimonios los soldados tendieron a exhibir la experiencia bélica de diversas maneras, lo cual resultaba difícilmente digerible para el nuevo orden. En muchos casos, reivindicaban la guerra que habían peleado y aun cuando eran más ambiguos respecto de esta posición, las heridas en sus cuerpos, las mutilaciones y el daño psicológico se volvían pruebas irrefutables de la experiencia bélica. Además muchos de ellos en las manifestaciones usaban los uniformes, lo cual a los ojos de la sociedad los ligaba al sector militar que, simultáneamente estaba siendo juzgado $\mathrm{y}$, en las primeras conmemoraciones participaron de hechos violentos,

\footnotetext{
11 Carlos Gamerro. "Tierra de la memoria”. Radar (Página 12). 11 de abril de 2010. Disponible en http://www.pagina12.com.ar/diario/suplementos/libros/10-3787-2010-04-11.html

12 Pilar Calveiro. "Memoria, política y violencia”; en Ralph Buchenhorst y Sandra Lorenzano (eds.). Políticas de la memoria. Buenos Aires, Gorla, 2007; pág. 57.
} 


\section{Lara Segade}

como la sustracción de la estatua del canciller George Canning de la Torre de los ingleses y la quema de banderas.

De modo que la manera de narrar Malvinas que se imponga será aquella que permita situarlos a ellos también como víctimas del gobierno dictatorial y así exonerar a la sociedad que los había enviado a pelear como héroes y los recibía ahora en medio del silencio y la vergüenza: tal será el relato que proveerá la película Los chicos de la guerra, solidario con el que el Nunca más proveyó para el período dictatorial. Sin embargo, es necesario trazar una diferencia fundamental: mientras el Nunca más es el resultado de una investigación oficial y es simultáneo además a la realización de un juicio, Los chicos de la guerra es una película ficcional. Por otra parte, el hecho de que esta película se base en un relato testimonial no hace más que reforzar las diferencias. En efecto, los testimonios de sobrevivientes del terrorismo de estado fueron pronunciados en un contexto oficial, que les otorgó legitimidad y los proveyó de un marco externo de fijación de, al menos, una verdad:

la verdad que se buscaba establecer no estaba en las formas del testimonio mismo, no dependía de la fuerza o de la convicción de la primera persona, sino de una construcción externa a ella. El horizonte de la verdad se situaba en la correlación de los testimonios, la relación con las pruebas, el cotejo de evidencias. Y lo más importante, cuando esos relatos se proyectaban hacia la sociedad, los testigos hablaban menos de sí mismos que de otros $(. . .)^{13}$

Entretanto, el contexto de recepción y circulación de los testimonios sobre la guerra de Malvinas fue muy diferente, ya que se produjeron en el marco de investigaciones periodísticas privadas, amparadas en muchos casos en la iniciativa comercial de las editoriales, como es el caso del libro Los chicos de la guerra y editorial Galerna o el de Así Lucharon, de Carlos Túrolo (1982) y editorial Sudamericana.

III.

Los chicos de la guerra es publicado en agosto de 1982 y en los siguientes dos años alcanza las trece ediciones, con sesenta y cinco mil ejemplares vendidos. La bajada del título dice: "Hablan los soldados que estuvieron en Malvinas". El libro consta de ocho entrevistas, realizadas por el periodista Daniel Kon a soldados que acaban de regresar del frente, precedidas por una breve presentación de cada historia escrita por el mismo Kon. Todos los entrevistados son soldados conscriptos clase 62. En el prólogo, Kon se refiere a ellos como los "protagonistas principales" de la guerra y los define como "esos bisoños combatientes, de 18 o 19

${ }^{13}$ Hugo Vezzetti. "El testimonio en la formación de la memoria social"; en Cecilia Vallina (ed.). Crítica del testimonio. Rosario, Beatriz Viterbo, 2009; págs. 23-34. 


\section{Lejos de la guerra}

años, a los que todo el mundo, desde el comienzo de las hostilidades en el Atlántico Sur bautizó como 'los chicos'”14. El periodista manifiesta haber encarado la investigación alentado por "la curiosidad, las ganas de saber". ${ }^{15}$ Pero se pregunta: ¿qué forma dale a esa empresa? Entrevé dos posibilidades: la primera supone "ahondar en lo estrictamente anecdótico, rescatar sólo las aristas más terriblemente dolorosas de estos testimonios"16. La segunda apunta a "intentar una interpretación desde cualquiera de los ángulos posibles (psicológico, sociológico, político, estratégico-militar, etc.)"17. Las dos conllevan riesgos: si se ahonda en lo anecdótico, el libro puede terminar convirtiéndose "en un mero catálogo del horror"18. En cuanto a proponer una interpretación de los hechos, Kon se declara poco idóneo y prefiere dejarlo en manos de los especialistas -psicólogos, sociólogos, políticos, estrategas militares-. Por otra parte, sin embargo, ambos caminos se le imponen. Lo anecdótico, dice Kon, no puede ni debe descartarse completamente: "El hecho concreto, potente, de la guerra, no era en estos muchachos una simple anécdota; la forma en que contaban su guerra ya era parte de ellos mismos"19. En cuanto a la interpretación, incluso prevalece:

Podría pensarse, finalmente, que esta tarea quedó a mitad de camino entre las dos posibilidades enunciadas. Creo, sin embargo, que sin defraudar las expectativas que lo anecdótico siempre despierta, puede servir como una sencilla pero útil herramienta para los que quieran o necesiten interpretar, explicar. Por los temas tratados durante las conversaciones con los chicos, que no excluyen lo anecdótico pero que, por momentos en forma intencionada, en otros, naturalmente, lo trascienden, lo espero así. ${ }^{20}$

Es decir que ya desde el prólogo se explicita que, mientras los relatos tienden a la anécdota, al periodista que los entrevista la anécdota le resulta incompleta si no puede funcionar, al menos para otros, más idóneos, como herramienta de conocimiento. Sin embargo, la separación no parece ser así de tajante: de la misma tendencia a narrar anécdotas de sus entrevistados nace la posibilidad de algún tipo de saber, que tal vez no coincida con las explicaciones sociológicas, psicológicas o políticas pero que sí contribuye a forjar un sentido.

Las experiencias traumáticas en general y las guerras en particular, suponen interrupciones no solo en el curso de la vida sino en el modo en que se la significa. Por eso, para quienes participan de ellas resultan muy complejas de significar con las palabras y los relatos con que suele contarse la vida. En su extenso análisis de los relatos de diversas guerras del siglo XX. Samuel Hynes señala que ni la razonable linealidad de la historia ni de la vida propia consiguen dar cuenta de la

\footnotetext{
${ }^{14}$ Daniel Kon. Los chicos de la guerra. Buenos Aires, Galerna, 1984; pág. 10.

15 Ibíd.; pág. 10.

16 Ibíd.; pág. 10.

17 Ibíd.; pág. 10.

18 Ibíd.; pág. 10.

${ }^{19}$ Ibíd.; pág. 10.

20 Ibíd.; pág. 11.
} 


\section{Lara Segade}

experiencia de la guerra. Es por ello que los relatos de guerra, que en algún sentido se asemejan a las biografías, difieren de ellas en un punto fundamental: mientras la autobiografía narra una vida continua, la guerra supone una interrupción, una discontinuidad respecto del mundo conocido.

Sin embargo, es por eso mismo que al volver al mundo ordinario los soldados sienten la necesidad de contar las historias de donde estuvieron con el objeto de aproximar la guerra al universo de lo conocido, de suturar el hiato en la medida de lo posible y de reinsertarse así en el universo lógico del que fueron sustraídos. Esa restitución, al menos parcial, de la continuidad es uno de los sentidos fundamentales de la narración. En relación con ello, Leonor Arfuch ha definido al testimonio -en tanto discurso inmerso en lo que denomina "espacio autobiográfico" - como una de las narrativas vivenciales. Retomando a Hans-Georg Gadamer, sostiene que "cada vivencia es un momento de la vida infinita", en tanto está "entresacada de la continuidad de la vida y al mismo tiempo se refiere al todo de esta". ${ }^{21}$ A su vez, son narrativas porque cuentan: "Se inscriben así, más allá del género en cuestión, en una de las grandes divisiones del discurso, la narrativa, y están sujetas por lo tanto a ciertos procedimientos compositivos, entre ellos, y prioritariamente, los que remiten al eje de la temporalidad". ${ }^{22}$ Desde esta perspectiva, la narrativa es, incluso, una dimensión configurativa de la experiencia, no algo ajeno a ella: "existe, entre la actividad de contar una historia y el carácter temporal de la experiencia humana, una correlación que no es puramente accidental". Existe, incluso, una "mutua implicación entre narración y experiencia". ${ }^{23}$

Así, la continuidad del relato permitiría tal vez suturar la interrupción en la vida trazada por la guerra, otorgándole un sentido. Es lo que sucede en uno de los libros más hermosos pero también menos conocidos de Malvinas: 5000 adioses a Puerto Argentino, un relato autobiográfico de largo aliento, que el ex combatiente Daniel Terzano publicó en 1985. El libro surge "de la necesidad de encontrar los lazos de unión de esa experiencia con mi vida tal como era antes y tal como es ahora" 24 , con el objetivo de resistir "la tensión que se establece entre una realidad que se ha deformado y un pensamiento que cuenta, para entenderla, con hábitos ya muy viejos". ${ }^{25}$ Es en esa dirección que se despliega el relato, centrado en el repliegue sobre Puerto Argentino durante los días finales de la guerra. El derrotero de esa subjetividad sustraída de su marco cotidiano y puesta en una guerra va apareciendo, en el relato, entremezclado con los episodios propiamente bélicos.

En contraposición, en Los chicos de la guerra los relatos no alcanzan a desplegarse, pues permanentemente son interrumpidos por las preguntas de un periodista que teme que su libro se convierta en un "catálogo del horror" y que,

\footnotetext{
${ }^{21}$ Leonor Arfuch. El espacio biográfico. Buenos Aires, Fondo de Cultura Económica, 2010; pág. 36.

22 Ibíd.; pág. 87.

${ }^{23}$ Ibíd.; pág. 88.

${ }^{24}$ Daniel Terzano. 5000 adioses a Puerto Argentino. Buenos Aires, Galerna, 1985; pág. 15.

25 Ibíd.; pág. 130.
} 


\section{Lejos de la guerra}

además, apunta a extraer alguna enseñanza de los relatos, para que así estos puedan contribuir con la explicación de los hechos. Las preguntas de Daniel Kon apuntan en muchos casos a provocar en los soldados las reflexiones que según la separación que traza no provienen del testimonio: "En una guerra, siempre un soldado es un número, una pequeña pieza en una gran estructura, ¿no?”26; “¿Y el hecho de haber convivido con la muerte hizo que tu actitud hacia ella cambiara? ¿Le tenés menos miedo, por ejemplo?”. ${ }^{27}$ A veces, las asociaciones de ideas parecen aproximar a Kon al rol de terapeuta del que, según se afirma en la Introducción, él mismo se sentía llamado por momentos a desempeñar: "las preguntas fueron apenas el hilo ordenador de un largo y tenso monólogo que, sin las bondades de una terapia genuina, tenía igualmente para ellos un efecto casi catártico (y al no ser yo terapeuta me dejaban exhausto y tensionado)". ${ }^{28}$ Así, por ejemplo, sobre el final de la entrevista con Guillermo, Kon saca el tema de la juventud, haciendo partir la pregunta de una reflexión: "Justamente esos cargos, el desinterés, el descreimiento, se hacen con frecuencia a los jóvenes. Para mucha gente, la imagen de un joven de hoy es la de un chico subido a un par de patines y aislado del mundo exterior por medio de un par de auriculares". ${ }^{29}$ Guillermo responde: "Bueno, en muchos casos esa es una imagen real (...) Se ponen eso en la cabeza y no les importa nada más, van para adelante (...)". Entonces Kon interrumpe la frase para introducir una asociación con un fragmento anterior del relato de Guillermo: "Como los gurkas". 30 Guillermo había dicho: "Algunos gurkas venían barriendo zonas con las Mag, las ametralladoras que pesan tres veces más que un fusil (...) No les interesaba nada, ni sus propias vidas". ${ }^{31}$ En la asociación de Kon, el temible combatiente nepalés que aparece en el relato de los combates finales, que fueron los más terribles, donde la vida estaba en riesgo permanentemente deviene un joven desinteresado que escucha su walk-man.

Muchas otras preguntas de Kon tienen un efecto similar, en la medida en que, por medio de un tono paternalista, el periodista pareciera reprender cariñosamente a los soldados por alguna de las conductas adoptadas durante la guerra o guiarlos en el camino para que por sí mismos se reencaucen. Estas preguntas suelen girar en torno a la cuestión de la muerte -haber matado o haber temido morir- y, sobre todo, al hecho de si los soldados robaron comida estando en las islas. Así, por ejemplo, en la entrevista con Fabián tiene lugar el siguiente diálogo, a propósito de cómo resolvían el tema de la comida:

-Matábamos ovejas, o a veces tratábamos de conseguir, de otro modo...

-No te preocupes; otros chicos ya me contaron que iban a robar la comida.

\footnotetext{
${ }^{26}$ Daniel Kon. Op. cit:; pág. 18.

27 Ibíd.; pág. 42.

28 Ibíd; pág. 11.

29 Ibíd.; pág. 45.

30 Ibíd.; pág. 45.

31 Ibíd.; pág. 37.
} 


\section{Lara Segade}

-Ah, ¿te lo contaron? Bueno, sí, íbamos a robar a los depósitos. Ves, yo nunca habría imaginado que alguna vez iba a tener que robar; para mí eso siempre había sido algo horrible. Sin embargo, tuve que robar para poder sobrevivir. ${ }^{32}$

Durante la entrevista con Juan Carlos, el paternalismo de Kon se ve reforzado por una interrupción de la madre, que apunta en la misma dirección que las del periodista: "Teníamos un brasero, y hasta le habíamos puesto luz eléctrica, porque habíamos conseguido 200 metros de cable, un portalámparas y una lámpara (Aquí lo interrumpe la madre. "Juan, decí la palabra", le dice). Bueno, sí, habíamos robado el cable, el portalámparas y la lámpara en una planta potabilizadora de agua que estaba cerca". ${ }^{33}$ En este fragmento, la tipografía permite percibir con claridad el modo en que dos discursos diferentes confluyen en un mismo relato, uno que apunta a contar la anécdota, otro que apunta a utilizarla con fines moralizantes.

A Guillermo, entretanto, Kon le pregunta: “¿Pensás que algunas de las cosas que esta guerra las enseñó pueden resultar peligrosas, en el futuro, para algunos de ustedes? Aprendieron a robar, a mentir, a ocultar". ${ }^{34}$ Se ve, allí, cuál es la pregunta fundamental que subyace a la mayor parte de estas intervenciones del periodista: ¿cómo van a integrarse estos jóvenes, marcados por la guerra, a la sociedad democrática? Las posibles huellas de la guerra representan un riesgo para la democracia, como manifiesta Kon en muchas de sus preguntas: "Otro peligro de esta posguerra es que ustedes, al haber aprendido durante la guerra tantas cosas (desde cuerear una oveja hasta enfrentar la muerte), sientan que, a pesar de su juventud, saben más que los demás, ya no tienen nada que aprender" 35 . Y en otra entrevista: "Otra preocupación de esta posguerra es cómo se van a adaptar ustedes a vivir en familia, a aceptar la autoridad de los padres, después de haber vivido experiencias que ellos desconocen". ${ }^{36}$

Así, los sentidos que Kon introduce desde afuera con sus intervenciones tienden a ubicar la guerra en un marco de excepcionalidad y lejanía, a insertar la guerra en un relato antibélico y a Malvinas en un relato desmalvinizador. El hecho de que el primer libro testimonial sobre Malvinas pueda pensarse en relación con la desmalvinización señala con precisión una de las principales paradojas que asumió el relato de la guerra. En ese sentido, las interrupciones del periodista replican la imagen de la guerra como interrupción, como hecho discontinuo respecto del presente y del futuro: tanto en términos biográficos como históricos, es la experiencia bélica lo que no llega a constituirse en relato. Y es por esa doble vía que ejercen la pasivización de los ex combatientes que muchas veces se ha notado: evitando que hablen de la guerra y hablando por ellos.

De modo que los ex combatientes quedaron, en la posguerra, atrapados entre dos fuerzas de signo contrario: un discurso pacificador y desmalvinizador que

\footnotetext{
32 Ibíd.; pág. 194.

33 Ibíd.; pág. 138.

34 Ibíd.; pág. 27.

35 Ibíd.; pág. 43.

36 Ibíd.; pág. 130.
} 


\section{Lejos de la guerra}

quería olvidar la guerra y borrar las huellas que había dejado en ellos para reinsertarlos en la sociedad como los chicos que eran antes de irse y el impulso de reivindicar y contar la experiencia bélica. Esas dos fuerzas narrativas en tensión, que definen la posición de los ex combatientes durante la democracia, resultan muy claramente visibles en las entrevistas de Los chicos de la guerra. Mientras por un lado las intervenciones de Kon interrumpen el relato de la experiencia bélica e intentan reinsertarlo en el marco discursivo del nuevo orden democrático, por otro lado los ex combatientes intentan hablar de la guerra.

Así, por ejemplo, el relato de la batalla final de Guillermo se extiende durante seis páginas, con una sola intervención del periodista, que no llega a desviar el relato -"Y en ese momento, ya en el combate final, ¿habías recobrado la conciencia del peligro, de la muerte?"- ${ }^{37}$ Allí, Guillermo, lejos de posicionarse como víctima, narra activamente un episodio bélico, del que ni siquiera lo distrae la muerte de un querido compañero, que es comprendida, por el contrario, dentro de la lógica de la guerra:

Allí quedó ese chico, tirado entre nosotros, que seguíamos combatiendo, y que unas horas antes habíamos estado jugando al truco con él. Pero no se habló más del tema. Estaba muerto y nosotros volvimos a la guerra. Yo lo conocía mucho, había estado charlando con él mil veces, conocía a su familia, por las cartas que le mandaban, pero ahora él estaba muerto, y no había que hablar más del tema. Lo único que se empezó a escuchar, otra vez, eran los gritos "cuidado, cuidado", cuando recomenzaron las bombas. A mí algunas me estaban pegando a cinco o seis metros, las esquirlas me pasaban por arriba de la cabeza. Hasta las esquirlas más chiquitas venían al rojo vivo. Yo tuve la suerte que ninguna me pegó, pero al lado mío vi cómo les caían sobre las camperas de duvet a algunos chicos y quemaban todo, las camperas, los pulóveres, las camisetas, hasta llegar a la carne. Creo que ninguno de los que estábamos metidos en el medio de ese infierno sentía miedo, a esa altura. En lo único que pensábamos era en salvar el pellejo. 38

Ariel, entretanto, llega a las islas con un problema en las rodillas que la interrupción del tratamiento y el clima de las islas agravan muchísimo -de hecho, cuando Kon lo entrevista, Ariel sigue muy dolorido y apenas puede caminar-. Llega a desmayarse de dolor durante la guerra. Sin embargo, lo disimula, porque quiere seguir peleando, no abandonar a sus compañeros en el momento más difícil:

Yo tenía las rodillas cada vez más negras, se me habían hinchado muchísimo, y me costaba caminar, pero no decía nada. Finalmente, conseguí hacer la guardia sentado, con permiso de un suboficial [...] A los pocos días, cuando terminó mi turno, me paré, se me nubló todo, y me caí desmayado [...] El capitán vino y me dijo: “¿Qué te pasa negro?". Le expliqué mi problema y al día siguiente me vino a avisar que me iba al continente. Le pedí por favor que me dejara un par de días más, a ver si mejoraba.

37 Ibíd; pág. 37.

38 Ibíd.; pág. 39. 


\section{Lara Segade}

Me sentía muy mal, teniendo que dejar a mis amigos allí, ahora que los ingleses ya habían desembarcado, y comenzaban a avanzar. ${ }^{39}$

En 1984 se estrena Los chicos de la guerra de Bebe Kamin. ${ }^{40}$ La película es una ficción basada en el libro de Daniel Kon, quien colaboró con la redacción del guión. En el marco de esta trasposición ficcional la película elabora una selección, en la que se toman, se recombinan y se agregan ciertos elementos del libro, del mismo modo en que otros se dejan afuera: entre estos últimos se destacan, en primer lugar, los episodios bélicos que acabamos de mencionar. Los combates ocupan una proporción ínfima del tiempo y además están narrados desde una perspectiva distante o no se ven porque transcurren de noche. En la película, desaparece por completo la voz de los soldados y, por tanto, su fuerza narrativa: quedan de ese modo a merced de un relato victimizador. En efecto, en el espacio que queda libre, lo que se desarrolla como relato es lo que en el libro de Kon aparecía desde afuera, por medio de las intervenciones del periodista.

En la película, tres historias sintetizan las ocho presentadas por Kon: mientras Fabián y Santiago duplican aproximadamente a personajes del libro -a los que se agregan anécdotas o características de otros y algunos pocos rasgos nuevos-, el caso de Pablo es diferente, ya que se trata de un personaje enteramente inventado. Es hijo único de un matrimonio de clase alta. Su padre, que tiene estrechos vínculos con los militares en el poder, no lo salva de ir al frente: quiere que cumpla con su deber patrio. En el film se destacan las historias personales: dónde estaba cada uno cuando lo sorprendió la convocatoria, cómo eran hasta entonces su vida y su familia, cómo vivió la guerra y cuál fue su destino; esto es, la dimensión privada, individual, que incluso es narrada desde las infancias de los protagonistas. Así, se refuerza el impacto de lo que la guerra generó, como interrupción, en esas vidas.

Como consecuencia de la magnitud dramática de esa interrupción, la reinserción será muy difícil, según la propuesta de la película, que concibe tres destinos posibles para los soldados en la sociedad democrática, a los que se agrega un cuarto, el de la muerte en las islas. Santiago, que pierde su empleo al volver de Malvinas, termina llevando una mala vida de borracho y pendenciero y finalmente acaba en la cárcel. Con Pablo aparecen la locura y el fantasma del suicidio: termina encerrado en un cuarto disparando a enemigos imaginarios con el rifle de caza de su padre. Fabián es el único para el que la película propone un desenlace aceptable: en la última escena se lo ve con su novia, presenciando un recital de Juan Carlos Baglietto.

Por otra parte, en el libro de Kon los entrevistados suelen afirmar que la experiencia de la guerra los volvió más conscientes políticamente y que despertó en ellos la voluntad de participar. Sin embargo, esta voluntad de participación

\footnotetext{
39 Ibíd.; pág. 68.

${ }^{40}$ La película, protagonizada por Héctor Alterio, Carlos Carella, Ulises Dumont, Marta González, Tina Serrano y Miguel Ángel Solá, entre otros, se estrenó el 2 de agosto de 1984 y fue un éxito de taquilla.
} 


\section{Lejos de la guerra}

política no forma parte de ninguno de los destinos propuestos por la película para los ex combatientes. Incluso, más ampliamente, podría decirse que la dimensión política en su totalidad está obturada en una película que elige contar la guerra desde la perspectiva de la peripecia individual y el sufrimiento humano. En la misma medida en que se desdibujan los lazos de los soldados con el presente democrático, se refuerzan, en la película, los lazos que unen la guerra con la dictadura y que sitúan a los soldados como sus víctimas. En ese sentido, cobra gran importancia el personaje de Santiago, que en el libro es el que más se detiene en el relato de los maltratos y hasta torturas de los superiores sobre los soldados e, incluso, cuenta que en un caso desató a un soldado que había sido estaqueado por ausentarse de su puesto de combate. El resultado es una película que exacerba el gesto de Kon en desmedro de algunos otros elementos, propuestos sobre todo por los soldados en sus testimonios: una película que "limpia" los relatos de aquello que pudiera resultar difícil de asimilar por la sociedad en la primera posguerra produciendo una ficción apta para el consumo del gran público. Fundamentalmente, la película termina de delinear una determinada imagen de los ex combatientes como víctimas pasivas del régimen militar que los llevó a la guerra. Si bien el gesto victimizador ya aparecía en el libro, allí todavía era tensionado por las voces de los soldados y sus "anécdotas" bélicas.

IV.

En el momento en que Daniel Kon inicia sus entrevistas a los soldados, Fogwill ya tiene terminada la primera novela de la guerra de Malvinas que, mecanografiada y fotocopiada, comienza entonces a circular entre algunos amigos y conocidos. En más de un sentido es posible afirmar que esa novela, Los pichiciegos, pone en escena el escenario discursivo al que nos referimos en el punto anterior: por un lado, paradójicamente, a partir de una historia que transcurre en los márgenes del campo de batalla y cuyos protagonistas son un grupo de desertores; por otro lado, a partir de la leyenda que Fogwill fue construyendo a lo largo de los años sobre las circunstancias que rodearon la escritura de la novela.

En efecto, en innumerables entrevistas, conferencias y paratextos Fogwill contó que en el momento en que estalló la guerra, vivía en el mismo edificio que su madre. Un día fue a visitarla y la encontró mirando televisión: Hundimos un barco, le dijo. Fogwill volvió a su casa y escribió: "mamá hoy hundió un barco". Ese fue el comienzo. El resto de la novela fue escrito entre el 11 y el 17 de junio de 1982, de un tirón, sin dormir y con doce gramos de cocaína. A veces, la cantidad de días son menos y los gramos de cocaína son más, pero en todos los casos se trata de una escritura veloz, urgida incluso, y simultánea respecto de la guerra. A la velocidad de la escritura se suma la velocidad de la primera circulación: en fotocopias, de mano en mano. Fogwill cuenta que "La novela tuvo al principio unos catorce ejemplares, y después fotocopias, que se editaron en Brasil. Ponele que esos 


\section{Lara Segade}

catorce ejemplares los hayan leído tres personas cada uno. Hay setenta y dos lectores del libro antes de que termine la guerra". ${ }^{41}$

Si esas historias resultan importantes es porque en ellas se advierte uno de los gestos fundamentales de Los pichiciegos: el de la simultaneidad respecto de los acontecimientos narrados. Y porque es de allí que surgen las lecturas de la novela en clave "profética": si verdaderamente fue escrita y comenzó a circular antes de que terminara la guerra o al menos antes del regreso de los primeros soldados, se vuelve anticipatoria respecto de la derrota argentina y de los modos en que los soldados habían vivido en Malvinas entre abril y junio.

Fogwill, por su parte, al mismo tiempo que difundió las historias que lo ubicaban escribiendo la guerra mientras ocurría, alentó las lecturas en clave "profética", aunque señalando que no se trataba de una adivinación sino de un "cálculo", elaborado sobre la base de una mirada lúcida sobre la realidad que consigue distinguir los elementos del futuro que ya están, en solución, en el presente de la escritura: "Usé la literatura como buzón (...) Yo deposito en clave un montón de datitos, para que vean que yo me avivé y que todos los demás son unos pelotudos. Es la venganza del tipo que entiende". ${ }^{42}$

Sin embargo, se enfrentó con vehemencia a quienes, en los ochenta, interpretaron estos pronósticos como parte de una posición pacifista o antibélica. En más de una oportunidad afirmó que Los pichiciegos no fue escrita "contra la guerra sino contra una manera estúpida de pensar la guerra y la literatura". ${ }^{3}$ Pues escribir contra la guerra sería como escribir contra la lluvia, los sismos o las tormentas. No se trata, por tanto, de embestir contra la realidad sino contra los modos de representar, desde la literatura, esa realidad, contra "las maneras equivocadas de nombrar". 44

En ese sentido, al mismo tiempo que desplaza la guerra del centro de la narración Los pichiciegos coloca allí la cuestión de los modos en que esa guerra es narrada, lo cual permite trazar una relación entre esos dos hechos -la ausencia de la guerra de los relatos, la forma que esos relatos asumieron en los primeros años de la democracia- antes de preguntarse cuáles son esas maneras estúpidas de nombrar contra las que Fogwill escribe a toda velocidad.

En primer lugar, conviene volver a la escena originaria de Los pichiciegos. El verdadero origen es la frase "Hundimos un barco" en boca de la madre apostada frente al televisor, y el efecto que provoca en Fogwill: "Ni la imagen de decenas de ingleses violetas flotando congelados, que de alguna manera me alegraba, pudo atenuar el espanto que me provocaba el veneno mediático inoculado a mi familia". ${ }^{45}$

\footnotetext{
${ }^{41}$ Martín Kohan. "Fogwill, en pose de combate". N (Clarín). 25 de marzo de 2006. Disponible en http://edant.clarin.com/suplementos/cultura/2006/03/25/u-01163931.htm.

42 Ibíd.; en línea.

${ }^{43}$ Rodolfo Fogwill. "Nota del autor a la séptima edición"; en Los pichiciegos. Buenos Aires, El Ateneo, 2010; pág. 11.

${ }^{44}$ Ibíd.; pág. 11.

45 Ibíd.; pág. 10.
} 


\section{Lejos de la guerra}

Aunque la frase "mamá hoy hundió un barco" finalmente no quedó en la novela, en el comienzo de Los pichiciegos quedó su huella. Allí todavía puede leerse el posicionamiento en contra del modo en que la guerra es presentada en televisión:

Que no era así, le pareció. No amarilla, como crema; más pegajosa que la crema. Pegajosa, pastosa. Se pega por la ropa, cruza la boca de los gabanes, pasa los borceguíes, pringa las medias [...] Imaginaba la nieve blanca, liviana, bajando en línea recta hacia el suelo y apoyándose luego sobre el suelo hasta taparlo con un manto blanco de nieve. Pero esa nieve, ahí, amarilla, no caía: corría horizontal por el viento, se pegaba a las cosas, se arrastraba después por el suelo y entre los pastos para chupar el polvillo de la tierra; se hacía marrón, se volvía barro. Y a eso llamaban nieve cuando decían que los accesos tenían nieve. Nieve: barro pesado, helado, frío y pegajoso. En el televisor la nieve es blanca. Cubre todo. Allí la gente esquía y patina sobre la nieve. Y la nieve no se hunde ni se hace barro ni atraviesa la ropa, y tiene trineos con campanillas y hasta flores. ${ }^{46}$

El comienzo delimita la zona en la que se va a desenvolver la historia: en lo bajo, en lo mugriento, lejos de las imágenes triunfalistas, pulcras y brillantes, de ribetes épicos, que se muestran por televisión. Ahora bien: "las maneras equivocadas de nombrar" contra las que Fogwill escribía Los pichiciegos no eran solo las de los medios de comunicación, sino que incluían la complicidad del público, establecida durante la guerra y mantenida en los años siguientes, aun cuando primaran el enojo y el estupor por el engaño sufrido. Y es que, en 1983, los medios de comunicación dejaron de representar al gobierno dictatorial y pasaron a asociarse con el nuevo gobierno democrático, aunque los términos de esta nueva asociación fueran tal vez más complejos, más indirectos que los de la etapa anterior. En ese sentido, cabe preguntarse ahora por el discurso que se genera en esta nueva forma de una antigua complicidad, en la medida en que, como veremos, es también contra él -tal vez fundamentalmente contra él- que se escribe Los pichiciegos.

En la sugestiva fecha de diciembre de 1983, Los pichiciegos abandona la clandestinidad para ser editada por Ediciones de la Flor. En la contratapa, Fogwill sostiene que Los pichiciegos está lejos de cualquier preocupación sobre el acontecimiento bélico; que, por el contrario, se refiere, entre otras cosas, a "la democracia que sobrevendría". Los pichiciegos, entonces, tal vez deba ser pensada como una novela de la transición de la dictadura a la democracia, antes que como una novela de la dictadura. Por ello, su verdadera premonición no es la derrota, que constituye en realidad un evento simultáneo a la escritura, sino la democracia: la forma que adoptará, cuáles serán sus relatos dominantes, sus "maneras equivocadas de nombrar". Fundamentalmente, se trata del discurso al que referimos antes que, ligado a la teoría de los dos demonios, quiso ver en Malvinas

46 Rodolfo Fogwill. Los pichiciegos. Buenos Aires, Interzona, 2006; pág. 11. 


\section{Lara Segade}

un hito que marcaba un antes y un después, completamente desconectados entre sí. En la medida en que, pese a todo, la novela es sobre Malvinas, se comprende que Malvinas prefigura la democracia o, en otras palabras, la democracia ya existe en solución en Malvinas. Así, Fogwill traza una línea que conecta no solo dictadura, Malvinas y democracia, sino también la dictadura con los años anteriores, e incluso, la democracia de los ochenta con el menemismo, en la que es posible "adivinar" el futuro.

En una serie de artículos publicados durante 1984, Fogwill hizo referencia a estas mismas cuestiones, confrontando y denunciando el discurso pacifista que primó durante la década del ochenta y que encubría una configuración de la sociedad como víctima, ajena a la violencia. ${ }^{47}$ Así, por ejemplo, responde Fogwill a unas declaraciones del doctor Alberto Cormillot acerca de la inhumanidad de los torturadores: 48

Pero -sucede- toda gorda en el fondo sigue siendo una gorda y algún día recae y vuelve a los dulces, a los hidratos de carbono, la celulitis y la fealdad, tal como toda sociedad puede volver a la picana, a los campos de concentración, a la monstruosidad inhumana, al pus de fondo. Habría que aniquilar las verdaderas causas de la gordura -de la aniquilación- y dejarse de ponerle sucaryl periodístico al sistema. Creer, como cualquier señora gorda, que los torturadores son inhumanos (...) es el menú para adelgazar conciencias que distribuyen hoy los medios que cantaban a los laureles eternos del orden y la paz mientras el país engordaba y se hinchaba de horror y de miseria $(. . .)^{49}$

Respecto de la masacre de Trelew, ocurrida en 1972, Fogwill afirma "que allí empezó la guerra sucia y no en 1976, como parecen creer los que quieren creer que ya está terminada". ${ }^{50}$ Entre esas continuidades, Fogwill destaca la de cierta terminología, una "herencia semántica" en la que se enmascaran las otras. Hablar de "desaparecidos" contribuye a igualar a todas las víctimas de la represión, borrando la diferencia entre las inocentes y las combatientes; del mismo modo, la expresión "dictadura militar" encubre la "dictadura oligárquico-financieramultinacional que comenzó a montarse en 1974" y que se continuó bajo otras formas hasta alcanzar su máximo poder en la década del noventa. ${ }^{51}$

Es, por tanto, en los modos de nombrar, es decir, en el uso de ciertas palabras y no en su prohibición, donde perduran e incluso se reproducen la violencia, la desigualdad y el caos en medio del orden y la paz de la primavera alfonsinista, que

\footnotetext{
47 Casi todos estos artículos fueron originalmente publicados en la revista El porteño, donde también se publicó un fragmento de Los pichiciegos en noviembre de 1983, a modo de anuncio. Una menor cantidad de artículos se publicaron en el semanario Primera plana. Todos ellos fueron reunidos en 2008 por editorial Mansalva en Los libros de la guerra.

48 Alberto Cormillot (Buenos Aires, 1938) es un médico argentino especializado en temas de obesidad, que ha desarrollado gran parte de su carrera en los medios de comunicación, donde frecuentemente hizo declaraciones sobre temas de actualidad como la que Fogwill responde aquí.

${ }^{49}$ Rodolfo Fogwill. Los libros de la guerra. Buenos Aires, Malnsalva, 2008; pág. 60.

50 Ibíd.; pág. 60.

51 Ibíd.; pág. 70.
} 


\section{Lejos de la guerra}

por este camino se revelan como meramente aparentes: "tal es la herencia del Proceso, verificada sin censura, sin persecuciones ni 'listas negras', con el sencillo recurso de una 'lista blanca' de temas y palabras que entusiasman a un público que, como siempre, necesita dormir entre los sueños que distribuye la cultura". 52

Así, durante la transición democrática, Fogwill insiste en señalar el trasfondo de violencia de las instituciones aparentemente pacíficas; que la guerra, lejos de oponerse a la paz, existe consubstanciada con ella, disimulada en ella. En Los pichiciegos, no hay un tiempo de paz y otro de armonía, separados. Por el contrario, la guerra está en las catacumbas de la paz, nutriendo sus raíces; la nieve se pegotea en el suelo con el polvo y se hace barro. En ese sentido, se comprende que, después de que la novela fuera elogiada por su realismo -de tinte profético-y su pacifismo, Fogwill haya escrito, en la contratapa de la primera edición, que no era una novela contra la guerra y, además, que se trataba de un experimento de ficción, compuesto antes de los primeros testimonios de los combatientes.

En ese sentido, la relación de Los pichiciegos con Los chicos de la guerra no se funda únicamente en una coincidencia temporal sino que, por el contrario, es señalada por la propia novela de Fogwill, donde es definida como una competencia en la que la misma "verdad" de la guerra de Malvinas que la ficción exhibe -su función de puente entre la dictadura y la democracia- es encubierta por el testimonio, que por lo tanto constituye una de esas maneras equivocadas o estúpidas de contar la guerra contra las que la novela dice estar escrita. ${ }^{53}$ Esta relación de competencia se define, en especial, en las distintas reflexiones que recorren e incluso estructuran Los pichiciegos respecto de las posibilidades que tiene la lengua de dar cuenta de la guerra: “Según él, 'desintegrado' no es la mejor palabra, tampoco 'derretido'. Tendría que encontrar una palabra que dijera lo mismo, entre 'desintegrado' y 'derretido', pero en la isla, en medio de la guerra, no había tiempo ni tampoco lugar donde buscar palabras mejores que explicaran las cosas". ${ }^{4}$

Fundamentalmente, esta reflexión se produce en lo que constituye una suerte de marco narrativo de la novela: los encuentros entre Quiquito, el único pichiciego sobreviviente, y un hombre que lo escucha y graba lo que él dice. Es en esos encuentros donde aparece una reflexión sobre las posibilidades de transmisión de la experiencia bélica. Permanentemente, Quiquito le pregunta a su interlocutor si lo está grabando y, sobre todo, si lo entiende y si le cree, y por momentos se enoja ante la presuposición de que no:

\footnotetext{
52 Ibíd.; pág. 65.

53 En entrevistas posteriores, Fogwill reafirmará la idea de una competencia entre su novela y el libro de Kon, que se establece tanto en el ámbito comercial -Los chicos de la guerra podía impedir, según Fogwill, la venta de Los pichiciegos- como en el ideológico: "Un vivo prometió editarlo, pero inspirado en las escenas del grabador de los pichis, encomendó a un periodista la compilación de relatos de sobrevivientes que tuvo éxito por su ingenuidad y su tono antibélico" (Rodolfo Fogwill. "Nota del autor a la séptima edición"; en Los pichiciegos, Buenos Aires, El Ateneo, 2010; pág. 11).

${ }^{54}$ Rodolfo Fogwill. Los pichiciegos. Op.Cit.; pág. 99.
} 


\section{Lara Segade}

- ¿Entendés?

- Sí -respondí convencido.

- No. ¡No me entendés! Seguro que a vos alguna vez habrán estado a punto de boletearte, fuiste preso, tuviste dolores en una muela o se murió tu viejo. Entonces, vos, por eso, te pensás que sabés. Pero vos no sabés. Vos no sabés. ${ }^{55}$

Resulta especialmente significativa la ambigüedad de la figura del entrevistador, que en función de algunas de sus intervenciones durante los encuentros, que se llaman "sesiones", podría considerarse un psicólogo. Por ejemplo: "Calentarse. Estuvimos dos semanas hablando sobre el frío y ahora llegamos a la cuestión de calentarnos ...".56 El mismo Fogwill ha mencionado "la escena del psicólogo" y ha hecho referencia a la incomprensión de los psicólogos que atendieron a los soldados a su regreso de Malvinas, de modo que el personaje bien podría aludir a ellos y parodiarlos.

Por otra parte, el hecho de que los encuentros se graben, sumado a las menciones a la preparación de un libro, apunta a la idea de que se trata de un periodista. Algunas de las preguntas que el personaje formula a Quiquito refuerzan esta idea. Por último, el entrevistador se convierte por momentos en escritor y alter ego de Fogwill, ya que, como él, acaba de publicar el libro de cuentos Música japonesa y, además, toma notas, es decir, escribe. Finalmente puede pensarse también que Quiquito es un alter ego, en diminutivo, de Quique Fogwill.

En la escena, pues, se ve que el énfasis de Los pichiciegos no está en la guerra sino en su relato: es en la literatura y el testimonio donde se cifran las principales posibilidades del relato de la guerra durante los inicios del gobierno alfonsinista. La variante de que el entrevistador sea un psicólogo incluye, además, una tercera posibilidad: la del testimonio dado por un paciente psiquiátrico que, como tal, pierde validez. En ese sentido, el psicólogo funciona, en la novela, como equivalente desvalorizado del periodista. ${ }^{57}$ En efecto, esta es la lectura que ha hecho de la novela Elsa Drucaroff, extremando la idea de Martín Kohan acerca del carácter eminentemente farsesco de Los pichiciegos. Para Drucaroff, el hecho de que todo el relato esté puesto en boca de Quiquito permite afirmar que es posible que toda la historia sea la fabulación psicótica de un "loco de la guerra"; aunque, en todo caso no importa, pues si hay algo que la novela de Fogwill postula ante todo es "la voluntad de no tomarse demasiado en serio". 58

Sin embargo, en Los pichiciegos, la farsa tiene un reverso dramático que se revela, en gran medida, en el diálogo entre Quiquito y su entrevistador, es decir, en el marco del relato, donde se formula la pregunta acerca de quién y cómo va a contar esta guerra. En ese sentido, llama la atención que la crítica literaria haya

\footnotetext{
55 Ibíd. [Pág. 95]

56 Ibíd. [Pág. 139]

57 Recordemos que, en el prólogo de Los chicos de la guerra, el mismo Daniel Kon afirmaba sentirse desempeñando funciones de terapeuta, rol que reproducía, por otra parte, en algunas de sus intervenciones.

${ }^{58}$ Elsa Drucaroff. Los prisioneros de la torre. Buenos Aires, Emecé, 2011; pág. 299.
} 


\section{Lejos de la guerra}

prestado relativamente poca atención a la escena del entrevistador, incluso cuando, en general, se trató de lecturas preocupadas por los modos en que la novela daba cuenta de la guerra, producía una verdad en torno a ella o anticipaba su resultado, cuestiones que justamente se ponen en juego en esa escena.

Esperablemente, no atendieron a la escena las primeras lecturas, que encontraron en Los pichiciegos un gesto pacifista. Pero tampoco la crítica de los años noventa se detuvo en ella. Entonces, las posiciones predominantes en la crítica literaria eran las que Beatriz Sarlo definió en relación con un pasaje "del sistema de la década del sesenta, presidido por Cortázar y una lectura de Borges 'contenidista', al sistema dominado por Borges y un Borges procesado en la teoría literaria que tiene como centro al intertexto". ${ }^{59}$ Este movimiento es el correlato, en sede literaria, de una cultura democrática y no revolucionaria que surge durante la "primavera democrática", cuando "las formas de hacer política del pasado reciente -la intransigencia de las facciones, la subordinación de los medios a los fines, la exclusión del adversario, el conflicto entendido como guerra- dejaban paso a otras en las que se afirmaba el pluralismo, los acuerdos sobre formas y una subordinación de la práctica política a la ética". ${ }^{60}$

En Los pichiciegos, la difusión de un relato en gran medida constituido por medio de los testimonios periodísticos y la consolidación de una crítica literaria que se centró en las incursiones de la literatura en lo real y no en las incursiones de lo real en lo literario, terminaron por borrar de la novela la escena testimonial que es, sin embargo, una de las formas principales en que Los pichiciegos se refiere a la democracia, o la anticipa. En efecto, la inclusión de una instancia testimonial en la novela remite a los discursos que primarán en democracia a la hora de hablar de Malvinas $\mathrm{y}$, por tanto, de la dictadura militar: discursos "ingenuos" $\mathrm{y}$ "antibelicistas" cuyo motivo principal será el de presentar la dictadura separada de la democracia, y a Malvinas como el episodio, ligado a la primera, que marca un antes y un después. ${ }^{61}$

\footnotetext{
${ }^{99}$ Sylvia Saítta. "La narrativa argentina, entre la innovación y el mercado (1983-2003)”; en Marcos Novaro y Vicente Palermo (comps.). La historia reciente. Buenos Aires, Edhasa, 2004; pág. 243. ${ }^{60}$ Ibíd.; pág. 243.

61 En los últimos años, esta situación comienza a modificarse, con películas como Iluminados por el fuego, que, pese a recuperar en parte el tono y los tópicos de Los chicos de la guerra, comienza también a intercalar escenas de la guerra producidas con tecnología y efectos especiales entre las escenas del drama de la posguerra o como El héroe del Monte Dos hermanas, relato heroico financiado por organismos oficiales del gobierno nacional y, sobre todo, con la aparición de una serie de poesías escritas por ex combatientes, género totalmente novedoso de estos años -Soldados, de Gustavo Caso Rosendi (2009); Haikus de guerra, de Martín Raninqueo (2012); Brilla tú, borracho loco, de Hugo Sánchez (2012)- que reconfiguran el mapa de los relatos de Malvinas, trastocando el orden de los vínculos entre lo literario y lo testimonial. Concomitantemente, parte de la crítica literaria comienza a detenerse en la escena testimonial "incrustada" en Los pichiciegos. Es el caso, por ejemplo, de Julieta Vitullo en Islas imaginadas. Cabe señalar, por otra parte, que ese libro dio lugar a un documental, La forma exacta de las islas, dirigido por Edgardo Dieleke y Daniel Casabé y estrenado en 2012, que constituye en sí mismo una mirada novedosa sobre Malvinas: las islas pero, también, la guerra.
} 


\section{Lara Segade}

\section{A modo de recapitulación}

A lo largo de los años, la guerra de Malvinas siguió siendo objeto de las más diversas elaboraciones narrativas: cuentos y novelas de escritores jóvenes y no tanto, incluso de algunos que con los años se consagrarían; películas, muchas veces con guiones originales y otras basadas en relatos escritos; eventualmente, canciones y poesías, en muchos casos compuestas por ex combatientes; y por supuesto, relatos testimoniales, algunos novelados, tanto de militares como de soldados, recopilados por periodistas, autogestionados, promovidos por editoriales o por instituciones ligadas a las Fuerzas Armadas. Mayormente, la crítica literaria abordó tan extenso y variado corpus a partir de distintas versiones de la hipótesis, originalmente propuesta por Martín Kohan, de que en la literatura argentina la guerra de Malvinas ha tendido a ser narrada más como farsa que como épica.

Sin embargo, tanto en las dos obras fundacionales que trabajamos aquí como en otras posteriores, pudimos constatar que los relatos no solo carecían de épica sino que, incluso, tampoco aparecía en ellos de modo contundente la guerra, esto es: las armas, las tácticas y estrategias, la posibilidad de matar y de morir, los combates contra un enemigo extranjero, las conductas heroicas. El gesto inaugural de Los pichiciegos, en ese sentido, no residió tanto en sus inflexiones farsescas que, por otra parte, se ven opacadas por el drama de una guerra que, sin constituir del todo un acontecimiento excepcional, funcionó como un puente conflictivo entre la dictadura y la democracia-, sino en el hecho de ubicar la acción en el margen de la guerra e instalar, simultáneamente, al desertor como personaje principal; es decir, elegir a quien abandona no solo la guerra sino también su lógica y su relato. Asimismo, observamos que esta doble debilidad -del relato épico y del referente bélico- no es un rasgo distintivo de lo que convencionalmente se entendería por literatura. Si bien los relatos testimoniales, en mayor o menor medida, incluyen escenas de combates, lo hacen pobremente en relación con el objetivo del que nacen: dar cuenta de la experiencia de guerra.

Entre las razones por las que la guerra de Malvinas no fue representada prioritariamente en los relatos que le estuvieron dedicados, hay una serie de cuestiones históricas: por un lado, el hecho de que la mayor parte del tiempo que los soldados pasaron en las islas haya sido de espera y no de combate; por otro lado, las dificultades que encontraron sus relatos para circular en los distintos momentos de la posguerra debido a esa suerte de mancha de origen de la guerra de Malvinas -la utilización, por parte de la dictadura, de una causa considerada justa; el hecho de que Malvinas se erigiera en puente de dos órdenes inconciliables como la dictadura y la democracia-. Si bien otras guerras compartieron alguno de estos rasgos -la Primera Guerra Mundial fue una guerra de trincheras con largos períodos de espera; Vietnam fue considerado por muchos como ilegítimo o vergonzante y la posguerra fue reacia a admitir un relato heroico-, ello no fue obstáculo para que se produjeran relatos que, con carácter bélico o antibélico, 


\section{Lejos de la guerra}

hicieron de la guerra el escenario principal y, de los hombres marcados por ella, sus protagonistas.

Por otro lado, existen también algunas cuestiones que ligan la experiencia de la guerra con la literatura y que explican la debilidad o casi ausencia del referente bélico en los relatos de Malvinas en relación con la dificultad de recurrir a la épica para contar esta guerra. Sabemos, desde Bajtín en adelante, que el relato épico se corresponde con un universo total y homogéneo, que no puede ser cambiado, reevaluado ni interpretado, y que hoy ese universo ya no existe, se ha aproximado y fragmentado, por lo que la épica, como tal, pertenece al pasado. Sin embargo, autores como Fredric Jameson sostienen que, pese a ello, todavía es posible recuperar algunos elementos de le épica que existe, entonces, como uno de los polos de una oscilación narrativa, como se advierte, de hecho, en las novelas y filmes de otros conflictos armados. En cambio, en los relatos de la guerra de Malvinas, priman la fragmentariedad y la confusión propias de la inmediatez perceptiva: no consiguen, casi en ningún momento, organizarse, resolver la oscilación.

Se tendió además, a obturar desde afuera el movimiento hacia lo épico. Los rasgos de heroicidad que aparecieron fueron borrados, o convertidos en victimización, según hemos visto en el pasaje del libro Los chicos de la guerra, de Daniel Kon, a la película de Bebe Kamin. Tal conversión constituye también un gesto fundacional que confluye con el que realizó Los pichiciegos, en tanto ambos implican un desplazamiento hacia el margen de lo bélico. A partir de allí, los soldados no pueden ser representados ni representarse a sí mismos como héroes en el sentido más amplio del término, esto es, como protagonistas del relato bélico, como guerreros. Durante la mayor parte del tiempo de posguerra, tal representación pareció inhibirse en relación con el hecho de que cualquier epicidad era asociada inmediatamente con el discurso militar. Los militares se instalaron en esa tradición, apropiándose del discurso bélico. Fueron ellos, en efecto, casi los únicos en hablar de combates, de estrategias, de armamentos, de héroes -los cuales, por otra parte, siempre eran ellos mismos-. Así, se reforzó la asociación entre relato épico y corporación militar. Hay que tener en cuenta, además, que los militares siempre hablaron de dos guerras -una en Malvinas, contra los ingleses, otra interna, contra la "subversión"-, de modo que la terminología bélica y las estructuras narrativas de la épica quedaron asociadas así, también, a la represión ilegal. En ese contexto, cualquier detentación, por parte de los soldados, de símbolos o palabras ligadas al universo de la guerra fue repudiada y excluida de los relatos. Entonces, al obturarse la posibilidad de que en los relatos de Malvinas aparezcan héroes, que enfrenten en combate a sus enemigos, que utilicen armas y que maten, es decir, en definitiva, la posibilidad de recurrir a la épica, lo que se obtura es, en líneas generales, la representación de la guerra entendida a partir de sus elementos más reconocibles. 


\section{Lara Segade}

\section{Bibliografía}

ARfuch. Leonor. El espacio biográfico. Buenos Aires, Fondo de Cultura Económica, 2010

BAjTíN, Mijaíl. “Épica y novela”; en Teoría y estética de la novela. Madrid, Taurus, 1989.

Calveiro, Pilar. "Memoria, política y violencia"; en Ralph Buchenhorst y Sandra Lorenzano (eds.). Políticas de la memoria. Buenos Aires, Gorla, 2007.

Caso Rosendi, Gustavo. Soldados. Buenos Aires, Ministerio de Educación de la Nación, 2009.

DruCAROFF, Elsa. Los prisioneros de la torre, Buenos Aires, Emecé, 2011.

FogWILL, Rodolfo. Los pichiciegos. Buenos Aires, Interzona, 2006.

---. Los libros de la guerra. Buenos Aires, Mansalva, 2008.

---. "Nota del autor a la séptima edición"; en Los pichiciegos, Buenos Aires, El Ateneo, 2010.

Foucault, Michel. Defender la sociedad. Buenos Aires, Fondo de Cultura Económica, 2010.

Gamerro, Carlos. "Tierra de la memoria”. Radar (Página 12). 11 de abril de 2010. Disponible en http://www.pagina12.com.ar/diario/suplementos/libros/10-37872010-04-11.html

GARDinI, Carlos. “Primera línea”; en Cuentos. Buenos Aires, Sudamericana, 1983.

HynES, Samuel. The soldiers' tale, New York, Penguin, 2001.

JAMESON, Fredric. Antinomies of Realism. London, Verso, 2013.

KoHAN, Martín et al. "Transhumantes de neblina, no las hemos de encontrar". Espacios de crítica y producción; N¹3. Buenos Aires, diciembre 1993 / marzo 1994.

Kohan, Martín. "El fin de una épica". Punto de vista; $\mathrm{N}^{\circ} 64$. Buenos Aires, agosto de 1999.

---. "Fogwill, en pose de combate". N (Clarín). 25 de marzo de 2006. Disponible en http://edant.clarin.com/suplementos/cultura/2006/03/25/u-01163931.htm.

Kon, Daniel. Los chicos de la guerra. Buenos Aires, Galerna, 1984.

LAmborghini, Osvaldo. "La causa justa"; en Novelas y cuentos II, Buenos Aires, Sudamericana, 2003.

LóPEZ, Fernando. Arde aún sobre los años. La Habana, Casa de las Américas, 1985.

LoRENZ, Federico. Las guerras por Malvinas. Buenos Aires, Edhasa, 2006. 


\section{Lejos de la guerra}

Perlongher, Néstor. “Todo el poder a Lady Di”, "La ilusión de unas islas” y "El deseo de unas islas"; en Prosa plebeya. Buenos Aires, Colihue, 1997.

RANINQUeO, Martín. Haikus de guerra. La Plata, El reloj de arena, 2011.

Rozitchner, León. Malvinas: de la guerra sucia a la guerra limpia. Buenos Aires, Losada, 2005.

SAíTTA, Sylvia. "La narrativa argentina, entre la innovación y el mercado (19832003)"; en Marcos Novaro y Vicente Palermo (comps.). La historia reciente. Buenos Aires, Edhasa, 2004.

SÁnchEz, Hugo Emilio. Brilla tú, borracho loco. Buenos Aires, Garrincha Club, 2012.

SCHVARTZMAN, Julio. Microcrítica. Lecturas argentinas (cuestiones de detalle). Buenos Aires, Biblos, 1996.

Soriano, Osvaldo. A sus plantas rendido un león, Buenos Aires, Seix Barral, 2008.

Speranza, Graciela. “Cómo se cuenta una guerra”. Clarín. Buenos Aires, 26 de marzo de 2000.2 Disponible en: http://edant.clarin.com/suplementos/cultura/2000/03/26/e-00601d.htm.

Terzano, Daniel. 5000 adioses a Puerto Argentino. Buenos Aires, Galerna, 1985

Túrolo, Carlos. Así lucharon. Buenos Aires, Sudamericana, 1982.

VezzetTI, Hugo. "El testimonio en la formación de la memoria social"; en Cecilia Vallina (ed.). Crítica del testimonio. Rosario, Beatriz Viterbo, 2009.

Vitullo, Julieta. Islas imaginadas. Buenos Aires, Corregidor, 2012. 